\title{
Proceedings of Business and Economic Studies
}

\section{Prospects for Science and Technology Cooperation between the Guangdong-Hong Kong-Macao Greater Bay Area and Portugal under the Belt and Road Initiative}

Jiaming Liang

Guangdong Science and Technology Evaluation Center, Guangzhou 510070, China

Funding: This paper is supported by the Guangdong Province Science and Technology Project "Guangdong Province IndustryUniversity-Research Collaborative Innovation Model" (2015A080804003)

Abstract: President $\mathrm{Xi}$, focusing on building a new pattern of all-round opening up to the outside world and promoting the common prosperity and progress of all countries, put forward a major proposal for the construction of the Silk Road Economic Belt and the maritime Silk Road in twenty-first Century. The bay area economy, as an important coastal economic form, is the highlight of the current international economic map, and is a significant symbol of the world's first-class coastal city. The international first-class bay areas, such as New York Bay area, San Francisco Bay area and Tokyo Bay area, are characterized by openness, innovation, livability and internationalization. The Guangdong-Hong Kong-Macao Greater Bay Area has four worldclass cities, name Guangzhou, Shenzhen, Hong Kong and Macao, and the Pearl River Delta city cluster. It has an open economic structure, efficient resource allocation ability, strong agglomeration and spillover function and development international communication network plays a core function of leading innovation and gathering radiation. It is an important growth pole for promoting the economic development of the maritime Silk Road and a leader in technological change. With the help of Portugal's geographical position on the maritime Silk Road and market access advantages within the EU system, the Greater Bay Area should further deepen scientific and technological cooperation, improve the ability of scientific and technological innovation of both sides, let the scientific research subjects of the bay area help
Portugal's scientific and technological development, and enhance Portugal's scientific and technological position in the EU. From the perspective of the Belt and Road Initiative, combined with the basic situation and cooperation of China, especially Guangdong, Hong Kong and Macau, and the development of science and technology in Portugal, this article explores the technological fields, policy measures that are suitable for scientific and technological cooperation between the two sides, and puts forward corresponding suggestions to contribute to the technological development of China, Portugal and the global economic and social sustainable development.

Key words: The Belt and Road Initiative; Guangdong-Hong Kong-Macao Greater Bay; Portugal; Science and technology cooperation

Publication date: December, 2020

Publication online: 30 December, 2020

"Corresponding author: Jiaming Liang, leungkaming @qq.com

\section{Introduction}

In the past 7 years, with the joint efforts of all participants, the the Belt and Road Initiative has increasingly become an open and inclusive platform for international cooperation and a global public product popular among all parties. Among the EU Member States, Portugal, Spain, Belgium, Italy, Luxembourg, Switzerland, Greece and other countries have joined in succession. China and Portugal jointly 
build the Belt and Road Initiative beyond the scope of bilateral cooperation, and further expand into the three party cooperation for Portuguese speaking countries and EU countries, and set a good example for the three party cooperation to build the Belt and Road Initiative. Portugal is a member of the European Union and the Portuguese speaking countries. It is a partner to build a the Belt and Road Initiative extension for Portuguese speaking countries and EU countries. In this context, how to learn from each other's strengths and make up for each other's weaknesses to improve the efficiency of regional scientific and technological innovation in the Greater Bay Area and Portugal is a problem of concern to the scientific and technological management departments of the two regions. In the past, the research object in China mainly focused on the scientific and technological cooperation between the two countries or between Macao and Portugal. The author believes that the Greater Bay area has more abundant scientific research resources than Macao, and can inherit the cooperation between Macao and Portugal. The channel of cooperation will certainly expand the scope of cooperation, and improve the level of cooperation compared with Macao, and deepen the level of cooperation compared with the national cooperation.

As early as 1993, China and Portugal signed an intergovernmental agreement on science and technology cooperation. For many years, science and technology cooperation between the two countries has been uninterrupted. On October 31, 2018, the China Portugal scientific and technological innovation cooperation seminar was held in Shanghai. Professor Paulo Ferrao, chairman of Portugal science and technology foundation, expressed his vision of cooperation with China in the fields of renewable energy, biology, agriculture, ocean and new materials. In December, Portugal and China signed a memorandum of understanding to build a the Belt and Road Initiative memorandum of understanding, and became the first Western European country to sign the agreement. A joint statement released on the same day by Portugal pointed out that Portugal welcomes and is willing to take part in the the Belt and Road Initiative initiative put forward by China. The two sides will actively deepen political dialogue and promote Eurasian connectivity and interconnection; the two sides are willing to strengthen cooperation with the third party countries in Africa and Latin America.(Cao, 2018) On July 12th, the ninth meeting of China Portugal Joint Commission on science and technology cooperation was held in Lisbon. Wang Zhigang, Minister of science and technology of China, and Manuel Heitor, Minister of science, technology and higher education of Portugal co-chaired the meeting. The representatives of government departments, scientific research institutions, universities and enterprises of the two countries review the cooperation achievements, discuss the development direction, gather innovative resources, and gather consensus on cooperation, so as to make a top-level design for future cooperation.

\section{General situation of scientific and techno- logical innovation}

This chapter will briefly introduce the advantageous technology fields, economic conditions and the division of labor in major cities in the Greater Bay Area, as well as the profile of the Portuguese foundation for science and technology(FCT). The basic conditions for cooperation between the two regions will be introduced.

\subsection{Development of science and technology in the Greater Bay Area}

The Greater Bay Area is a manufacturing cluster in China, which is known as the "world factory", with the GDP of 1.52 trillion US dollars and the population of 70 million, accounting for about $10 \%$ of the national manufacturing industry.(The development plan for Guangdong-Hong KongMacao Greater Bay Area, 2019) One of the important tasks of building the Greater Bay Area is to build a world-class advanced manufacturing base. In recent years, the manufacturing structure of the Pearl River Delta has been gradually upgraded, especially the proportion of technology intensive manufacturing and high-tech industries has increased, such as electronic information, equipment manufacturing, new materials, biomedicine and other advanced manufacturing industries have accounted for more than $50 \%$, and the proportion of high-tech industries has exceeded $30 \%$; there are a number of worldfamous high-tech industries such as Huawei, China Southern Power Grid, Guangzhou Automobile Group, Tencent, Midea, Gree and Lenovo Technology enterprises are expected to build an international 
science and technology innovation center.

It is proposed to promote the construction of "Guangzhou Shenzhen Hong Kong Macao" science and technology innovation corridor, explore policies and measures conducive to cross-border flow and regional accommodation of innovative elements such as talents, capital, information and technology, and build a big data center and international innovation platform of the Greater Bay Area.(Development planning outline of Guangdong Hong Kong Macao Bay Area, 2019) Hong Kong is an international financial center, Guangzhou is a political, economic and cultural center, and Shenzhen is a scientific and technological research and development center. However, due to its special language, history and cultural background, Macao has become a unique platform for China Portugal cooperation, playing an irreplaceable role in the communication and interaction between China and Portuguese speaking countries in the fields of economy, society and culture. In this case, connecting FCT through Macau is a viable option.

\subsection{Portuguese foundation for science and techn- ology}

The Portuguese foundation for science and technology (FCT) is one of the main management institutions of Portuguese competitive scientific research funds. Its budget is mainly from the supporting investment of national finance, supplemented by the funds of the European Union. Each year, FCT provides about 400 million euros of research and development costs to the whole society, accounting for about $30 \%$ of Portugal's public budget in the field of science. (Lin, 2016) According to the EU innovation assessment report released by the European Commission in 2017, Portugal's innovation capability has increased by 4 places compared with 2016, ranking 14th in the EU Member States, making the best record. In the process of promoting scientific and technological cooperation, we should give full play to the role of the foundation in Portugal's scientific and technological innovation system. In the next chapter, the author will introduce the current situation of cooperation between Portugal, China and Macau, and some of them are through FCT.

\section{General situation of scientific and technol- ogical cooperation}

Since there is not much cooperation between the Greater Bay Area and Portugal currently available for research, by analyzing the existing cooperation foundations between China and Portugal, the author hopes to find out the model and entry point of the scientific and technological cooperation between the Greater Bay Area and Portugal.

\subsection{Cooperation between China and Portugal}

According to incomplete statistics, Chinese enterprises and citizens have invested more than 9 billion euros in Portugal, and Portugal has become the fifth largest target country for Chinese investment in Europe. As one of the largest international investors in Portugal, Fosun has invested more than 2.15 billion euros in banking, insurance and medical fields since it entered the market in 2014. In recent years, the Three Gorges group and Energias de Portugal(EDP) have jointly developed the Brazilian hydropower market and the wind power market of Britain, Germany, Italy and other countries. After completing the energy infrastructure network in Portugal, China State Grid Corporation and Redes Energéticas Nacionais, SGPS, S.A(REN) have cooperated to build energy pipelines in Chile. (Ministry of foreign affairs of PRC, 2018) This means that the current cooperation between the two countries is mainly based on the participation of large Chinese groups in Portuguese companies, but these Chinese groups are not from the Greater Bay Area.

Portugal is the first European Union country to formally establish a "blue partnership" with China. It is the first euro zone country to issue UnionPay cards and issue RMB bonds by local important financial institutions, and financial cooperation has increasingly become an important growth point of Sino Portuguese the Belt and Road Initiative cooperation. According to FCT public information, the Sino Portuguese science and technology cooperation program received the applications of 27 projects, and supported 10 projects in 8 technical fields in 2016, but unfortunately none of these projects is from the Greater Bay Area. In 2019, Portugal launched another cooperation program in the fields of environmental protection and marine biotechnology with Macao, and FCT budgeted 300 
thousand euros to support the projects.(FCT, 2019) It can be seen that there can be two entry points for scientific and technological cooperation. One is to mobilize large-scale technology companies in the Greater Bay Area, and the other is to make full use of the platforms of Macau and FCT. The cooperation mechanism will be explained in detail in the next section.

\subsection{Main cooperation mechanism}

The joint committee mechanism of science and technology cooperation between the two countries is one of the important and high level mechanisms of the comprehensive strategic partnership between the two countries. In recent years, under the framework of the mechanism, the two countries have built a number of joint research platforms in the fields of advanced bioengineering materials, strengthening collaborative innovation in marine science and technology, online translation of digital solutions and quality assessment, which are playing an active role in promoting personnel exchanges, joint research, integration of production, learning and research, technology transfer and achievement transformation between the two sides. The author believes that through the joint committee mechanism, the Department of science and technology of Guangdong Province, the Hong Kong Innovation and Technology Bureau, the Science and Technology Development Fund of Macao and FCT can establish a long-term science and technology cooperation mechanism between the Greater Bay Area and Portugal, give full play to the platform role of the Macao forum, actively attract and connect global innovation resources, and build an open, interconnected and reasonably distributed regional innovation system.

In addition, on the basis of financial cooperation, we will further open the field of science and technology finance, and promote financial institutions of China and Portugal to invest in high-tech industries of both sides. The author thinks that we should support in-depth cooperation in the field of risk investment, give full play to the capital markets and financial services functions of Macao, and work together to build a diversified, international and cross regional investment and financing system for technological innovation. After analyzing the general situation of innovation and cooperation between the two regions, in the next chapter, the author will briefly point out the benefits that the two places should have in cooperation.

\section{Advantages of cooperation}

\subsection{From the perspective of the Greater Bay Area}

There are four advantages for the Greater Bay Area, by carrying out scientific and technological cooperation with Portugal. First, Portugal has special geographical location, science and technology center of emerging companies, perfect transportation and logistics facilities, stable investment environment and low corporate income tax and other environmental advantages. Second, it has high-quality employees and flexible labor market. Portugal has a large number of engineering related professional labor force; third, with the access advantages of the European Union, the scientific research subjects of the Greater Bay Area have the opportunity to further learn and adapt to the innovation methods and innovation system of the European Union; fourth, the unique relationship with Portuguese speaking countries in Africa and Latin America has a special platform role, which is very beneficial to the enterprises of the Greater Bay Area who want to go global.

\subsection{From the perspective of Portugal}

For Portugal, scientific and technological cooperation with the Greater Bay Area is also conducive to its own development. First, it can make up for the shortage of scientific research funds. Second, it helps to increase the number of scientific research talents. The impact of high-end brain drain caused by the past economic crisis still exists. At the same time, other more developed countries within the European Union attract talents from Portugal. The above is an analysis of the benefits from a top-down perspective. In the next chapter, the author will try to find the fields suitable for the cooperation from a bottom-up perspective.

\section{Possible fields of cooperation in the future}

According to the analysis and comparison of the advantageous fields of science and technology in the Greater Bay Area and Portugal, the following seven fields have certain research basis for both sides, and there are appropriate support carriers to carry out cooperation. 


\subsection{Traditional Chinese medicine}

The modernization of traditional Chinese medicine has the most Chinese characteristics and is a popular technology in Portuguese speaking countries. In the Greater Bay Area, there are major innovation carriers such as Macao platform for the development of Chinese medicine science and technology industry, Hengqin Guangdong Macao cooperative Chinese medicine science and Technology Industrial Park. Although Confucius Institute of Coimbra University is built on the basis of Zhejiang University, it is the first Confucius Institute with Chinese medicine characteristics in Portugal. The cooperation between the two sides can promote the modernization of traditional Chinese medicine to the international level, as an important supplement to Portugal and even the Western medical system, and enhance the recognition and acceptance of traditional Chinese medicine in the EU.

\subsection{Information Technology}

In 2016, Portuguese Prime Minister Antonio Costa said in an interview that Huawei has invested in technology and infrastructure in Portugal and created a technology innovation center. Cooperation between Huawei and Portugal Telecom can drive more Chinese enterprises to invest in Portugal. The software industry is a relatively developed industry in Portugal. Some equipment operating systems of Microsoft, Intel, NASA and ESA use Portuguese software technology. At the same time, Hong Kong Science Park and Hong Kong digital port are the key international science and Technology Parks in the Greater Bay Area. At present, there are R\&D centers of famous enterprises such as Huawei, NVIDIA, Siemens, Philips, Hitachi and so on. If advanced software enterprises from Portugal can be introduced into the Park, it is also conducive for these enterprises to enter the Chinese market.

\subsection{Marine technology}

Portugal used to be the No.1 maritime power, and is still a relatively advanced country in marine science and technology. The Belt and Road Initiative includes a lot of infrastructures such as ports, even in Portugal. The two regions can further connect with the highquality elements such as science and technology, management, supply chain and talents in the value chain of marine industry, and focus on promoting the technical service capacity and shipping guarantee of deep-sea transportation operation and marine resource development, marine ecological environment protection, disaster prevention and mitigation and other key marine scientific and technological innovation, to solve a number of basic and applied technology, to promote innovation in business model, management system and other aspects with marine scientific and technological innovation.

\subsection{Nanotechnology}

The national nanoscience center, Portuguese international nanomaterial, covers nanomaterials, nano characterization, nanomedicine, nano information sensing, nano energy and other fields. It is also an important part of international cooperation of the Chinese Sciences Academy. In Hongkong, the research center of nanomaterials and advanced materials is also a research institution engaged in related research.

\subsection{Life science}

The Shenzhen national gene library has launched the Belt and Road life science and technology promotion alliance, and the center for neuroscience and cell biology of Coimbra university is a nonprofit research organization established in 1990 to promote biomedical research and multi-disciplinary postgraduate teaching in Coimbra University. For many years, it has been steadily expanding the scope of scientific capabilities, focusing on the fundamental mechanisms of aging and brain diseases. For example, with the advantage of Huada gene sequencing, it can faster promote the knowledge exchange of Life Sciences.

\subsection{New energy vehicles}

The research shows that Portugal is the first country in Europe to build a complete charging facility for electric vehicles. In recent years, with the enhancement of residents' awareness of environmental protection and the continuous improvement of electric vehicle technology, the demand of electric vehicles in Portugal also shows a geometric growth.(Liu, 2018) The biggest passenger car manufacture plant in Portugal is Auto Europa Automóveis, Lda located in Palmela which produces about $90 \%$ of the passenger car while most of them are exported, that means all of the electric vehicles in Portugal are imported, among which the brands were mainly Tesla and BMW. 
(ACAP, 2019) BYD and Guangzhou Automobile Group in the Greater Bay Area are both technology leaders of new energy vehicles. If these car giants have the intention to cooperate, it will be possible to provide electric vehicles with more reasonable price for Portugal and the European Union.

\subsection{Clean energy technology}

China has become a world leader in solar photovoltaic, high-voltage energy transportation and electric vehicles. The energy markets in Europe and China are very diverse, but all countries share the same goal of developing clean energy and avoiding excessive dependence on external energy supply. The Belt and Road Initiative can not only greatly boost investment, but also help reduce carbon emissions. Fernandez, Portugal's minister of environment and energy, said that Portugal is vigorously implementing the energy production and consumption revolution, accelerating the process of re electrification, increasing investment in power grid, and exploring grid interconnection projects with neighboring countries to achieve zero carbon emissions by 2050. During the process of energy transformation and development, Portugal has established good cooperative relations with China's national Power Grid Corp and the Three Gorges group, relying on joint venture R\&D centers to carry out power grid frontiers technology research and sharing experiences in power grid operation and management. As a power grid management company in southern China, China Southern Power Grid can also participate in the cooperation.

Despite the many possibilities for cooperation, in the face of complex international factors, there may still exist problems that impede the cooperation, the next chapter will try to find out a few of them.

\section{Possible problems}

The author combines the international situation in the past two years and the skeptical opinions which has encountered on the Belt and Road Initiative, and attempts to hypothesize two of the issues that may affect cooperation between the Greater Bay Area and Portugal.

\subsection{Impact of the trade war}

In the context of the rise of global trade protectionism, some countries have doubts about the introduction of Chinese capital. However, in the past 10 years, Portugal 's economy has been booming due to opening up, and even in strategic industries, such as energy, there are a large number of Chinese investments. And Portugal is a European country that has benefited more from the Sino US trade war which was negative for the world economy, but the transfer of import demand from China and the United States to other markets would benefit some industries in some countries. The author suggests that China and Portugal should correctly understand the international situation and further deepen cooperation on the principle of mutual benefit. The relations between the two countries are stepping into the best period in history. A solid and sound bilateral relationship and the consensus and pursuit of serving the people's well-being with science and technology, promoting the progress of human civilization and coping with global challenges are the important basis for the two sides to carry out exchanges and cooperation in scientific and technological innovation.

\subsection{Impact of intransparency in international cooperation}

There are many fields involved in science and technology, the market is scattered, and the lack of transparency in national policies is a common phenomenon. Asia and Europe should create a more integrated, interconnected and competitive market. Science and technology policies of transnational cooperation lack transparency in many countries, because cutting-edge science and technology may also involve political issues. In the process of promoting the Belt and Road Initiative, the use of funds and land, judicial transparency and debt openness are all important factors affecting the confidence of the two countries. The author suggests to give full play to the role of embassy and consulate, strengthen communication with cooperative countries, establish an information disclosure system as soon as possible, picture a good image of international cooperation between the two countries and build the trust of partners.

\section{Conclusion}

7.1 The two regions have good cooperation conditions, but the current situation is not ideal

For the better scientific resources exchanges in the 
cooperation network, we should work together to create the Belt and Road technological innovation cooperation brand, encourage more large innovation entities in the Greater Bay Area to enter Portugal, and constantly improve the support mechanism for cooperation in the fields, projects and talents. The increasing demand and awareness of innovative projects in the Greater Bay Area, will further provide opportunities for Portuguese enterprises to develop innovative projects.

7.2 There are many high-level consultation mechanisms between the two countries and the two regions. If the role of the Macau platform and several pairs of friendly cities can be fully utilized, and strengthen information exchange, more cooperation should be promoted

The two regions should continue to strengthen the docking of science and technology innovation strategy and planning, give full play to the unique and irreplaceable role of Macao, and also make use of the three pairs of friendly cities of Zhuhai and Castelo Branco, Guangzhou and Coimbra, Shenzhen and Porto. The author thinks that people and business circles in the Greater Bay Area still don't know enough about Portugal. The government's job is to fully introduce Portugal to the people and ensure that people see it as a competitive and innovative destination.

7.3 Promoted by the Belt and Road Initiative, deepening cooperation between the two regions will bring many advantages in various fields

We should deepen practical cooperation in the fields of medical treatment, electronic information, artificial intelligence, ocean, materials, energy, space and climate change, create a good environment for scientific research, technological development and scientific and technological cooperation between the two regions, promote scientific and technological innovation cooperation, contribute more to the development of comprehensive strategic partnership, and contribute to the sustainable development and even the global economy and society contribute to science and technology.

7.4 In international cooperation, the existence of problems is inevitable. The key is whether the two sides can stick to the same interests and make continuous adjustments to maintain cooperation

Investment in science and technology is different from that in real estate and stock market, which requires long-term planning. Therefore, it takes time to plan and launch new projects. The Belt and Road Initiative plays a unique role in promoting investment in science and technology. Although the process is gradual, for avoiding the impacts from the trade wars and asymmetries in international cooperation, success requires more determination and patience from the governments and people of the cooperative countries or regions.

In the end, I wish greater success in the cooperation between the two regions.

\section{References}

[1] Cao Xu (2018) “An exclusive interview with Du Aojie, Portugal's ambassador to China: Portugal hopes to become a gateway to Europe on the Belt and Road" China Economic Weekly. 18, 44-45+88.

[2] Lin XianLan (2016) "The impact of EU regional policies on Portugal's national technological innovation capacity" China Science and Technology Forum. 09, 148-154.

[3] Wang Lin; Zhong Shuhua (2018) "Comparison of evaluation system of innovation capability between China and EU based on the report analysis of 2017 EU Innovation Scoreboard" Scientific research. 36 (09), 1716-1728.

[4] Chen Mingbao (2019) "Promoting the development of marine economic cooperation in the Guangdong-Hong Kong-Macao Greater Bay Area” China Ocean Daily. 23 de julho, 002.

[5] Liu Yusong (2018) “A new opportunity for Sino Portuguese economic and trade cooperation to build a belt." China Trade Daily. 11 de decembro, 004. 